\title{
Surface ligand controls silver ion release of nanosilver and its antibacterial activity against Escherichia coli
}

This article was published in the following Dove Press journal:

International Journal of Nanomedicine

I8 April 2017

Number of times this article has been viewed

\author{
Yan-Min Long ${ }^{1,2}$ \\ Li-Gang $\mathrm{Hu}^{1,3}$ \\ Xue-Ting Yan ${ }^{1,3}$ \\ Xing-Chen Zhao ${ }^{1,3}$ \\ Qun-Fang Zhou ${ }^{1,3}$ \\ Yong $\mathrm{Cai}^{2,4}$ \\ Gui-Bin Jiang ${ }^{1,3}$ \\ 'State Key Laboratory of \\ Environmental Chemistry and \\ Ecotoxicology, Research Center for \\ Eco-Environmental Sciences, Beijing, \\ China; ${ }^{2}$ Institute of Environment and \\ Health, Jianghan University, Wuhan, \\ Hubei, China; ${ }^{3}$ College of Resources \\ and Environment, University of \\ Chinese Academy of Sciences, Beijing, \\ China; ${ }^{4}$ Department of Chemistry \\ and Biochemistry, Southeast \\ Environmental Research Center, \\ Florida International University, \\ Miami, FL, USA
}

Correspondence: Qun-Fang Zhou Research Center for Eco-Environmental Sciences, Chinese Academy of Sciences, No 18 Shuangqing Road, Haidian, Beijing 100085, China

Tel +861062849334

Fax +86 I0 62849339

Email zhouqf@rcees.ac.cn
Abstract: Understanding the mechanism of nanosilver-dependent antibacterial activity against microorganisms helps optimize the design and usage of the related nanomaterials. In this study, we prepared four kinds of $10 \mathrm{~nm}$-sized silver nanoparticles (AgNPs) with dictated surface chemistry by capping different ligands, including citrate, mercaptopropionic acid, mercaptohexanoic acid, and mercaptopropionic sulfonic acid. Their surface-dependent chemistry and antibacterial activities were investigated. Owing to the weak bond to surface Ag, short carbon chain, and low silver ion attraction, citrate-coated AgNPs caused the highest silver ion release and the strongest antibacterial activity against Escherichia coli, when compared to the other tested AgNPs. The study on the underlying antibacterial mechanisms indicated that cellular membrane uptake of $\mathrm{Ag}, \mathrm{NAD}^{+} / \mathrm{NADH}$ ratio increase, and intracellular reactive oxygen species (ROS) generation were significantly induced in both AgNP and silver ion exposure groups. The released silver ions from AgNPs inside cells through a Trojan-horse-type mechanism were suggested to interact with respiratory chain proteins on the membrane, interrupt intracellular $\mathrm{O}_{2}$ reduction, and induce ROS production. The further oxidative damages of lipid peroxidation and membrane breakdown caused the lethal effect on E. coli. Altogether, this study demonstrated that AgNPs exerted antibacterial activity through the release of silver ions and the subsequent induction of intracellular ROS generation by interacting with the cell membrane. The findings are helpful in guiding the controllable synthesis through the regulation of surface coating for medical care purpose.

Keywords: silver nanoparticles, surface chemistry, silver ion release, Trojan-horse-type mechanism, respiratory chain, oxidative stress

\section{Introduction}

Due to the excellent antimicrobial effects of nanosilver against a wide range of microbes, such as bacteria, fungi, and even some viruses, this kind of nanomaterial is becoming more and more popular. ${ }^{1}$ Its disinfection efficiency has been widely explored in diverse aspects, including water treatment, medical care, and food packages. Since 2013, nanosilver-related commercial products have expanded to $>400$ types and occupied more than one-half of the nanotechnology-based consumer product amounts, ${ }^{2}$ revealing the increasing demands and promising commercial values in the production of nanosilver.

Currently available studies have indicated that nanosilver with different characteristics may exert distinct antibacterial capabilities against diverse microorganisms. For example, the minimum inhibitory concentrations (MICs) of silver nanoparticles (AgNPs, $13.4 \mathrm{~nm}$ ) were 6.6 and $33 \mathrm{nM}$ for Escherichia coli and 
Staphylococcus aureus, respectively. ${ }^{3}$ Another study indicated that the effective growth inhibition concentrations of myramisin-capped AgNPs with the particle size of $10 \mathrm{~nm}$ were 2.5 and $5 \mu \mathrm{M}$ for these two bacteria, respectively. ${ }^{4} \mathrm{As}$ for the commercial silver nanopowder, the colony forming units (CFU) of E. coli were completely inhibited when the exposure concentration was $300 \mu \mathrm{g} / \mathrm{mL} .{ }^{5}$ Apparently, the factors, including particle size, surface capper, and the particle shape, greatly influenced the antibacterial abilities of nanosilver. On-purpose design for the time- and dose-controllable formula of AgNPs has been an important subject regarding the optimization of their antibacterial properties in related commercial products.

The surface ligand-dependent chemistry and potential biological effects have been widely discussed for diverse nanomaterials, including AgNPs. ${ }^{6-8}$ Under ambient condition, $\mathrm{O}_{2}$ molecule would chemisorb on AgNPs and oxidize the surface $\mathrm{Ag}$ atom into monovalent ion of $\mathrm{Ag}^{+}$. It is supposed to be one of the key reactions contributing to the antibacterial activity of AgNPs. ${ }^{1,9-12}$ Controlled release of biologically active silver from nanosilver can be regulated by the surface ligands. Due to the relatively higher silver ion release ratio, citrate-capped AgNPs significantly enhanced the antibacterial zone of $E$. coli, when compared to 11-mercaptoundecanoic acid-capped AgNPs based on the Kirby-Bauer disk susceptibility test. ${ }^{12}$ In contrast, the dissolution rate and the amount of silver ions from polyvinylpyrrolidone-stabilized AgNPs were higher than those from citrate-stabilized AgNPs, because citrate coating was relatively more efficient in preventing silver ions from releasing. ${ }^{13}$ Branched polyethylenimine-capped AgNPs with positive charges tended to adsorb more on the membrane of gram-positive bacteria than did neutral polyvinylpyrrolidonecoated AgNPs and negatively charged citrate-coated AgNPs, thus causing more effective sterilization. ${ }^{14}$ Accordingly, the modification of AgNPs with surface ligands based on the adjustment of their coordination atom, carbon chain length, or the terminal group is very promising in regulating the antibacterial activities of AgNPs.

Understanding the antibacterial mechanisms of AgNPs is helpful in guiding the rational design and synthesis of ideal products, as this still remains ambiguous. $\mathrm{O}_{2}$ molecules may chemically adsorb on the 111 facet of AgNP surface and then be incompletely reduced to reactive oxygen species ( $\mathrm{ROS}, \cdot \mathrm{OH}, \mathrm{O}_{2}^{-} \cdot$ ). The biologically active radical species are capable of attacking the cell membrane, posing oxidative stress, or even causing death to the cells. ${ }^{15-17}$ Meanwhile, the released silver ions can approach negatively charged cell membrane and interfere with its integrity. ${ }^{1}$ Moreover, the internalized AgNPs through endocytosis or pinocytosis may pose a Trojan-horse-type effect, releasing silver ions in the cytoplasm through the reactions with organelles such as mitochondria. ${ }^{1}$ The intracellular silver ions can directly bind with the thiol-containing enzymes, such as respiratory chain complex I, causing the interruption of electron transfer and ROS production that induces oxidative stress and lesions to cells. ${ }^{18,19}$ Thus, whether the extracellular ROS generated from AgNP surface or interrupted cellular machinery induced by a Trojan-horse-type effect leads to the intracellular hazardous effects still remains an open question.

Previous studies on surface-coating effect of AgNPs were based on the commercially available AgNPs, ${ }^{3}$ which might limit the rational comparison of AgNP effects mediated by the different ligand structural factors. In this study, four types of $10 \mathrm{~nm}$-sized AgNPs with different organic ligands, including citrate (Cit), mercaptopropionic acid (MPA), mercaptohexanoic acid (MHA), and mercaptopropionic sulfonic acid (MPS), were intentionally prepared, with regard to the structural factors of coordination atom, carbon chain length, and terminal group. Using E. coli in $2 \mathrm{mM} \mathrm{NaHCO}_{3}$ as the experimental model, the ligand-dependent chemistry and the antibacterial activity of AgNPs were evaluated. The results indicated that the tested nanosilver exerted antibacterial activities in both time- and concentration-dependent manners. The capabilities of nanosilver in inhibiting bacteria were ascribed to the surface ligand-mediated silver ion release from both extracellular process and intracellular manner through a Trojan-horse-type effect. The studies using Cit@ AgNPs showed that internalized AgNPs caused cell damage through binding with the respiratory chain-related proteins and interrupting the electron transfer process. The findings herein have provided a promising strategy for the intended construction of nanosilver by surface chemistry regulation on the basis of understanding its underlying antibacterial mechanism.

\section{Materials and methods The synthesis and characterization of AgNPs}

The Cit@AgNPs was synthesized according to the previously reported method. ${ }^{20}$ In brief, $5 \mathrm{mM}$ sodium citrate (Sinopharm) and $25 \mu \mathrm{M}$ tannic acid (Sigma-Aldrich) were added into the $250 \mu \mathrm{M} \mathrm{AgNO}{ }_{3}$ (Sinopharm) solution. The mixture was continuously stirred and refluxed until the solution turned to light yellow. Cit@AgNPs was purified by ultrafiltration (10 kDa cutoff; Millipore) and washed twice with deionized 
water. The suspension $(40 \mu \mathrm{g} / \mathrm{mL})$ was stored at $4^{\circ} \mathrm{C}$ in darkness until use.

The other three kinds of nanoparticles, including MPA@ AgNPs,MHA@AgNPs, and MPS@AgNPs, were synthesized by ligand exchange, which included mixing and overnight stirring $20 \mu \mathrm{g} / \mathrm{mL}$ Cit@AgNPs (6.0 nM) and the respective ligand molecules of $264 \mu \mathrm{g} / \mathrm{mL}$ MPA, $64 \mu \mathrm{g} / \mathrm{mL}$ MHA, and $108 \mu \mathrm{g} / \mathrm{mL}$ MPS (Alfa-Aesar) in $10 \mathrm{mM}$ phosphate-buffered saline (PBS) (pH 7.4) at ambient temperature. The concentrations of the ligands were selected based on the optimization of ligand/AgNP molar ratio in preliminary studies, ie, the molar ratios of MPA, MHA, and MPS to AgNPs were 50,000:1, $500,000: 1$, and 10,000:1, respectively. The unreacted reagents were removed by ultrafiltration, and the products were further washed with deionized water twice to obtain the MPA@ AgNPs, MHA@AgNPs, and MPS@AgNPs. The prepared NP suspensions were kept at $4^{\circ} \mathrm{C}$ in darkness.

The morphologies of AgNPs were observed with transmission electron microscopy (TEM, 2100f; JEOL). The measurements, including X-ray photoelectron-binding energy analysis (AXIS UltraDLD; Kratos), UV-vis absorption (DU-800; Beckman), hydrodynamic size, and zeta potential (Mastersizer 2000; Malvern), were conducted to characterize the surface modification of these four kinds of AgNPs.

As for the determination of silver ion release, the asprepared four AgNPs were resuspended in the exposure medium of $2 \mathrm{mM} \mathrm{NaHCO}_{3}$ (Sinopharm) at the concentrations of 1,5 , and $15 \mu \mathrm{g} / \mathrm{mL}$, respectively, and incubated at $37^{\circ} \mathrm{C}$ under shaking ( $220 \mathrm{rpm}$ ) for 6 and $24 \mathrm{~h}$. The filtrates obtained by ultrafiltration with $3 \mathrm{kDa}$ cutoff membrane (Millipore) were used for the quantification of silver ion release. After sufficient digestion of filtrates by acid mixture $\left(65 \% \mathrm{HNO}_{3}: 30 \%\right.$ $\mathrm{H}_{2} \mathrm{O}_{2}, 1: 1$; Sinopharm), inductively coupled plasma mass spectrometry (ICP-MS, Agilent 8800) was utilized to quantify the released silver ions from AgNP suspension.

\section{AgNP exposure to $E$. coli}

One colony of E. coli (MG 1655) was inoculated into liquid Luria-Bertani (LB; Sigma-Aldrich) medium and grew at $37^{\circ} \mathrm{C}$ under shaking. The aliquots of suspension $(200 \mu \mathrm{L})$ were collected at intervals of 30 or $60 \mathrm{~min}$ for the determination of the optical density at $600 \mathrm{~nm}\left(\mathrm{OD}_{600}\right)$ using UV-vis spectrophotometer (DU-800; Beckman) to plot the growth curve of $E$. coli. The exponential growth phase of $E$. coli was reached after $3 \mathrm{~h}$ culture in LB growth medium, according to the growth curve (Figure S1). Therefore, E. coli entering into this rapid growth period was used for the exposure experiments.
The exposure of $E$. coli was conducted according to the previously reported protocol. ${ }^{21}$ After $3 \mathrm{~h}$ incubation, E. coli was centrifuged, washed, and resuspended in $2 \mathrm{mM} \mathrm{NaHCO}_{3}$ at the concentration of $10^{7} \mathrm{cfu} / \mathrm{mL}$. The exposure groups included AgNPs $(1,5$, and $15 \mu \mathrm{g} / \mathrm{mL})$ and $\operatorname{AgNO}_{3}(5,20$, 50,200 , and $1,000 \mathrm{ng} / \mathrm{mL}$ ). The treatment was performed on a shaker at $37^{\circ} \mathrm{C}$ with the rotary speed of $220 \mathrm{rpm}$. After $6 \mathrm{~h}$ exposure, the mixture was centrifuged at $1,000 \times \mathrm{g}$ for 5 min. The precipitate was washed with $\mathrm{NaHCO}_{3}$ medium. The pellet of $E$. coli was resuspended in $100 \mu \mathrm{L}$ of LB culture medium and transferred to the transparent 96-well plate. The treated E. coli grew in the incubator (KS 4000i control, IKA ${ }^{\circledR}$, Staufen, Germany) overnight at $37^{\circ} \mathrm{C}$ under the rotary speed of $220 \mathrm{rpm}$. The values of $\mathrm{OD}_{600}$ were determined to evaluate the viabilities of $E$. coli upon diverse stimuli.

The additional exposure groups were also designed to investigate the antagonistic effects of glutathione (GSH) (Sigma-Aldrich) and $\mathrm{Na}_{2} \mathrm{~S}_{2} \mathrm{O}_{3}$ (Sinopharm) on AgNPs and silver ions, respectively. More specifically, E. coli was stimulated with $\operatorname{AgNPs}(1,5$, and $15 \mu \mathrm{g} / \mathrm{mL})$ or $\mathrm{AgNO}_{3}$ $(5,20,50,200$, and $1,000 \mathrm{ng} / \mathrm{mL})$ in the presence of $1 \mathrm{mM}$ GSH or $0.1 \mathrm{mM} \mathrm{Na}_{2} \mathrm{~S}_{2} \mathrm{O}_{3}$ for $6 \mathrm{~h}$, respectively. The bacterial viability in each group was evaluated as described earlier. Regarding the antagonistic effects of these two chemicals in toxicological studies, four exposure groups including $15 \mu \mathrm{g} / \mathrm{mL}$ Cit@AgNPs, $15 \mu \mathrm{g} / \mathrm{mL}$ Cit@AgNPs plus 1 mM GSH, $15 \mu \mathrm{g} / \mathrm{mL}$ Cit@AgNPs plus 0.1 mM Na $\mathrm{S}_{2} \mathrm{O}_{3}$, and $0.5 \mu \mathrm{g} / \mathrm{mL} \mathrm{AgNO}_{3}$ were set up, and $E$. coli in each group was stimulated for $6 \mathrm{~h}$. After the exposure was terminated, the bacterial samples were washed with PBS and submitted to the subsequent pretreatments for the morphological observation, silver uptake evaluation, $\mathrm{NAD}^{+} / \mathrm{NADH}$ ratio test, malonyldialdehyde (MDA), and 8-oxoguanine assays.

\section{Morphological observation of E. coli}

After the exposure, E. coli from each group was resuspended in $2.5 \%$ glutaraldehyde/PBS (SP1-CHEM). The fixation was processed overnight at $4^{\circ} \mathrm{C}$. The dehydration was successively performed using 30, 50, 70, 80, 90, 95, and 100\% ethanol (Sinopharm). Isobutyl acetate (Sinopharm) was used to replace ethanol for scanning electronic microscope (SEM, SU8020; Hitachi) observation.

\section{$\mathrm{Ag}$ uptake and distribution by $\mathrm{E}$. coli}

E. coli samples from the control, $15 \mu \mathrm{g} / \mathrm{mL}$ Cit@AgNP, and $0.5 \mu \mathrm{g} / \mathrm{mL} \mathrm{AgNO}_{3}$ exposure groups were submitted to the digestion with $2 \mathrm{~mL}$ of acidic mixture $\left(65 \% \mathrm{HNO}_{3}: 30 \% \mathrm{H}_{2} \mathrm{O}_{2}\right.$, $1: 1$; Sinopharm) for the determination of total $\mathrm{Ag}$ uptake. 
The equivalent $E$. coli samples from exposure groups were lysed via intermittent sonication on ice for $1 \mathrm{~min}$. The samples were subsequently centrifuged at $30,000 \times g$ for $30 \mathrm{~min}$. The supernatant and precipitate were separately collected and digested to obtain the membrane and cytoplasm fractions of E. coli. Silver concentrations in both fractions were quantitatively measured with ICP-MS for Ag distribution in E. coli.

\section{$\mathrm{NAD}^{+} / \mathrm{NADH}$ ratio test}

The assay of $\mathrm{NAD}^{+} / \mathrm{NADH}$ ratio was used to evaluate the disturbance of AgNPs on the respiration chain in E. coli. The exposed samples were treated with $0.2 \mathrm{M} \mathrm{NaOH}$ and $0.2 \mathrm{M}$ $\mathrm{HCl}$ (Sinopharm) at $100^{\circ} \mathrm{C}$ for $10 \mathrm{~min}$ to extract NADH and $\mathrm{NAD}^{+}$, respectively. After 5 min centrifugation, the supernatant samples were collected and analyzed using the $\mathrm{NAD}^{+}$/ NADH Assay Kit (ab65348; Abcam).

\section{Intracellular ROS assay}

$E$. coli were exposed using the similar protocol to other assays, such as morphological observation and $\mathrm{NAD}^{+} / \mathrm{NADH}$ ratio. After the exposure was terminated, E. coli in each group was incubated with ROS probe of $10 \mu \mathrm{M}$ 2,7-dichlorodihydrofluorescein diacetate (DCFH-DA) (Sigma-Aldrich) at $37^{\circ} \mathrm{C}$ for $30 \mathrm{~min}$. After removing the redundant probes outside cells, the fluorescent signal $\left(\lambda_{\mathrm{ex}} / \lambda_{\mathrm{em}}=484 / 525 \mathrm{~nm}\right)$ was measured with the microplate reader (Varioskan ${ }^{\circledR}$ Flash; Thermo Fisher Scientific, Waltham, MA, USA) to evaluate the intracellular ROS production in the exposed E. coli.

\section{MDA generation in E. coli}

The content of MDA in AgNP-exposed E. coli was quantified by the lipid peroxidation assay kit (Abcam). Briefly, the bacteria were harvested and washed with cold PBS after exposure. Then, the cells were homogenized in MDA lysis buffer and centrifuged at $13,000 \times g$ for $10 \mathrm{~min}$. The supernatant was collected for MDA measurement. MDA in samples reacted with thiobarbituric acid (TBA) and formed adducts with red color. The level of MDA production in each exposure group was quantified according to the specific absorbance of adducts at $532 \mathrm{~nm} .^{22}$

\section{8-Oxoguanine determination using liquid chromatography-mass spectrometry/mass spectrometry (LC-MS/MS)}

The oxidative stress can induce DNA damage, resulting in the formation of 8-oxoguanine (8-oxo-dG). After the stimulation, $E$. coli sample from each group was extracted and processed for enzymatic hydrolysis using Bacterial DNA Kit (Omega). The levels of 8-oxo-dG were measured with LC-MS/MS using the pair ions of $m / z 284 / 168$ as the quantitative ions. The detection limit of the analytical method was $2 \mathrm{nM}$.

\section{Statistical analysis}

All the data were acquired from three independent experiments, and the values were expressed as average \pm standard deviation. The statistical analysis was performed using Student's $t$-test. The significant difference was demonstrated by $P<0.05$.

\section{Results and discussion \\ Characterization of AgNPs}

AgNPs with particle size not more than $10 \mathrm{~nm}$ exhibited surface-dependent ion release and toxicity. ${ }^{7}$ In this study, the monodisperse citrate-coated AgNPs of $\sim 10 \mathrm{~nm}$ were synthesized by chemically reducing silver citrate with trace tannic acid according to the previously reported method. ${ }^{20}$ The characterization results of the prepared nanoparticles are presented in Figure 1. The size distribution of Cit@AgNPs based on TEM image is $10.2 \pm 2.3 \mathrm{~nm}$. X-ray photoelectron spectroscopy (XPS) data in Figure S2 reveal the doublet $\mathrm{Ag} 3 \mathrm{~d}$ peaks at 368.2 and $374.2 \mathrm{eV}$, demonstrating that $\mathrm{Ag}$ core of Cit@AgNPs mainly stays at zero valence. C1s spectra can be fitted into four peaks with the corresponding binding energies of $\mathrm{C}-\mathrm{C}, \mathrm{C}-\mathrm{O}$, free $\mathrm{O}=\mathrm{C}-\mathrm{O}$, and $\mathrm{Ag}$ coordinated $\mathrm{O}=\mathrm{C}-\mathrm{O}$ of citrate (Figure S2). ${ }^{23,24}$ Thus, based on electronic effect and steric effect, the interface structure as shown in the cartoon (Figure 1) was suggested. Citrate ligand capped the thermodynamic-stabilized AgNPs through the coordination of two carboxyl groups to the surface Ag atoms. The other free carboxyl group in citrate oriented outward and constituted the outer layer of AgNPs, resulting in negative surface charges (-47.4 mV) of Cit@AgNPs and high stability in aqueous dispersion.

The selection of the other three ligands was based on the structural factors including the coordination atom (O or $\mathrm{S})$, carbon chain length $(3 \mathrm{C}$ or $6 \mathrm{C})$, and the terminal group $\left(-\mathrm{COO}^{-}\right.$or $\left.-\mathrm{SO}_{3}^{-}\right)$. These factors could control the surface $\mathrm{Ag}$ atom activity, $\mathrm{O}_{2}$ access, and $\mathrm{Ag}^{+}$release of the synthesized AgNPs. The exchange of the surface citrate with free ligands of MPA, MHA, and MPS on silver core produced MPA@AgNPs,MHA@AgNPs, and MPS@AgNPs, respectively. Considering the replacing ligands were superfluous in the reactions and they had relatively higher binding affinities to Ag surface than citrate, these three synthesized AgNPs were qualified for the subsequent experiments after the ligand exchange equilibrium reached and the complete wash of the products with deionized water using $10 \mathrm{kDa}$ cutoff ultrafiltration devices. The TEM images showed 


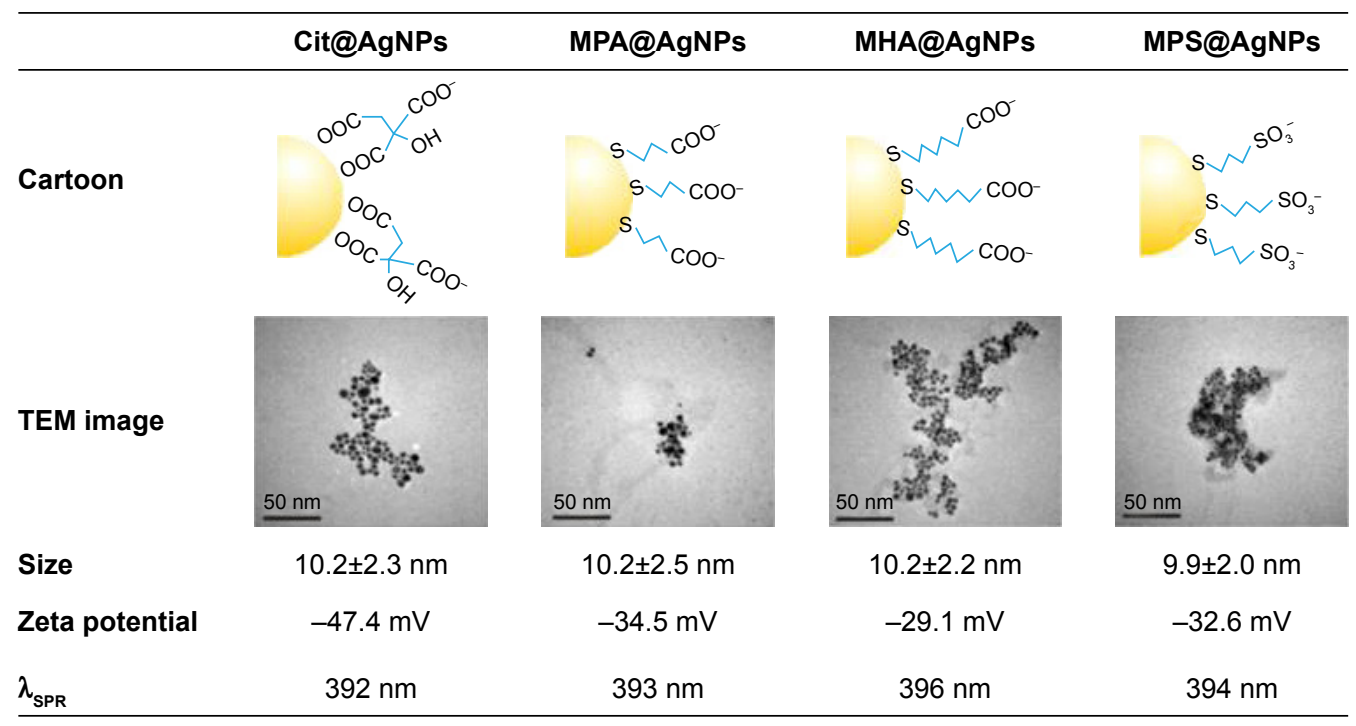

Figure I The cartoon depiction and the physicochemical parameters of four AgNPs tested in this study.

Abbreviations: AgNPs, silver nanoparticles; Cit, citrate; MPA, mercaptopropionic acid; MHA, mercaptohexanoic acid; MPS, mercaptopropionic sulfonic acid; SPR, surface plasmon resonance; TEM, transmission electron microscope.

that they were spherically shaped and monodispersive. The respective particle sizes were 10.2 \pm 2.5 nm for MPA@ AgNPs, 10.2 \pm 2.2 nm for MHA@AgNPs, and 9.9 $\pm 2.0 \mathrm{~nm}$ for MPS@AgNPs. The similar particle sizes of the four synthesized AgNPs showed that no changes in particle aggregation occurred during the surface ligand exchange of the nanoparticles. XPS data in Figure S2 indicate that they share similar characteristics: 1) AgNPs have a weakened resolved peak of $\mathrm{Ag}$ coordinated $\mathrm{O}=\mathrm{C}-\mathrm{O}$ and an enhanced peak of $\mathrm{C}-\mathrm{S}$ in $\mathrm{C} 1 \mathrm{~s}$ spectra, and 2) the doublet electronicbinding energy for S2p spectra is decreased. This suggested that instead of citrate, the ligands of MPA, MHA, and MPS anchored to the surface of AgNPs through the coordination between thiol groups and Ag atom, thus forming MPA@ AgNPs, MHA@AgNPs, and MPS@AgNPs, respectively.23,24 In addition, the S2p spectra of MPS@AgNPs showed a fitted peak at $167.9 \mathrm{eV}$ assigned to the sulfonic acid group of MPS molecule. ${ }^{25}$ The free carboxyl groups and sulfonic acid in outer layers of AgNPs endowed them with the negatively charged surfaces, and the zeta potentials in water were -34.5 mV for MPA@AgNPs, -29.1 mV for MHA@ AgNPs, and -32.6mV for MPS@AgNPs. The maximum absorbance of surface plasmon resonance (SPR) was in the narrow range of 392-396 nm, indicating the dispersion systems for these four AgNPs were robust and the particles had high monodispersity.

\section{Surface ligands regulate silver ion release from AgNPs in vitro}

Until now, the question as to whether the released silver ions or ROS mainly explain AgNP-induced antibacterial activities has been hotly debated. Herein, silver ion release from four as-prepared AgNPs in $2 \mathrm{mM} \mathrm{NaHCO}_{3}$ solution was determined after 6 and $24 \mathrm{~h}$ incubation at $37^{\circ} \mathrm{C}$. The results shown in Figure 2A and B indicate that ionic silver levels in the solutions exhibit both concentration- and time-dependent increase. Namely, silver ion release increased with AgNP concentrations ranging from 1 to $15 \mu \mathrm{g} / \mathrm{mL}$. As the incubation time proceeded from 6 to $24 \mathrm{~h}$, AgNPs released more silver ions into the solution. Silver ion release from AgNPs could be explained by the in vitro process in which the ambient $\mathrm{O}_{2}$ contacted and chemosorbed on AgNP surface, subsequently oxidized core $\mathrm{Ag}^{0}$ into $\mathrm{Ag}^{+}$that freely diffused into the surrounding solutions. ${ }^{9}$ When the effect of the surface ligand on silver ion release from AgNPs was investigated, it was found that during the monitoring time scale (6-24 h), AgNPs in $\mathrm{NaHCO}_{3}$ released silver ions in the following order: Cit@AgNPs > MPS@AgNPs > MPA@ AgNPs > MHA@AgNPs. For example, at the concentration of $15 \mu \mathrm{g} / \mathrm{mL}$, the ionic silver released from AgNPs was 68.9 ng/mL for Cit@AgNPs, 35.8 ng/mL for MPS@ AgNPs, 22.1 ng/mL for MPA@AgNPs, and $18.9 \mathrm{ng} / \mathrm{mL}$ for MHA@AgNPs after $24 \mathrm{~h}$ incubation at $37^{\circ} \mathrm{C}$. In contrast to the other three AgNPs with sulfur atom of the ligands binding on the surface, the ligand of citrate anchored to the surface of silver core through oxygen atoms with relatively weaker binding affinity, facilitating adsorption exchange with surrounding $\mathrm{O}_{2}$, and further oxidative dissolution of $\mathrm{Ag}^{0} .^{26,27}$ The shortest carbon chain of citrate among four tested ligands had the weakest capacity for oxygen isolation and caused the highest dissolution of $\mathrm{Ag}^{0}$ via easiest exposure access of silver core to environmental $\mathrm{O}_{2} \cdot{ }^{28}$ Among 
A

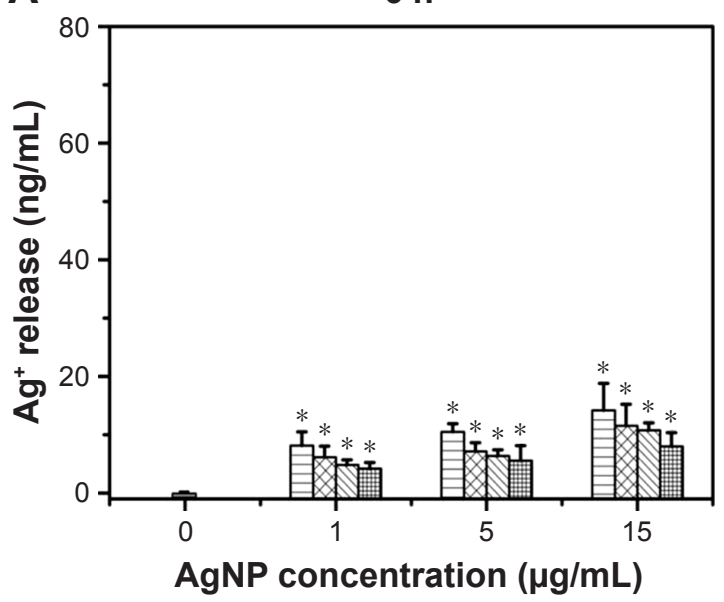

B

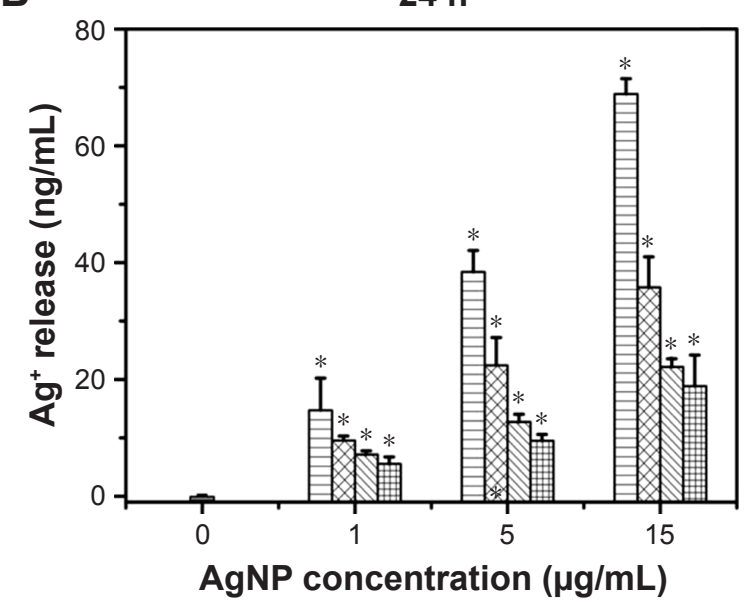

Cit@AgNPs MPS@AgNPs M MPA@AgNPs MHA@AgNPs

Figure 2 The surface ligand regulates silver ion release from AgNPs in both concentration- and incubation time-dependent manners.

Notes: The incubation lasted for (A) $6 \mathrm{~h}$ and (B) $24 \mathrm{~h}$. $* P<0.05$ versus the blank control.

Abbreviations: AgNPs, silver nanoparticles; Cit, citrate; MPA, mercaptopropionic acid; MHA, mercaptohexanoic acid; MPS, mercaptopropionic sulfonic acid.

three AgNPs coated with thiol groups, the terminal group of $-\mathrm{SO}_{3}^{-}$in the ligand MPS had lower affinity to release $\mathrm{Ag}^{+}$ than $-\mathrm{COO}^{-}$, thus causing less dissolved silver ions retaining on the particle surface and more ions being liberated to the surrounding solution. ${ }^{9}$ According to the results described earlier, the determined silver ion release order for all four tested AgNPs was closely dependent on their surface ligands. Therefore, the theoretical design through structural ligand regulation might specifically control the silver core oxidation by ambient $\mathrm{O}_{2}$ and the further release of silver ions, which could subsequently be involved with their biological effects. This also offered a promising approach for uncovering the underlying mechanism for AgNP-induced antibacterial activities by synthesizing diverse AgNPs with the specific characteristics to be tested.

\section{AgNPs produce antibacterial activities via a Trojan-horse-type mechanism}

E. coli can be cultured in simple media, such as $\mathrm{NaHCO}_{3}$, which has little effect on chemistry and bioavailability of the active species produced by nanosilver. Thus, E. coli in $2 \mathrm{mM}$ $\mathrm{NaHCO}_{3}$ was used as the model organism to study the antibacterial activities and the related mechanism of nanosilver. As shown in Figure 3A, when the exposure concentrations were controlled at 1,5 , and $15 \mu \mathrm{g} / \mathrm{mL}$, all four AgNPs exhibited an obvious concentration-dependent inhibition on E. coli viability after $6 \mathrm{~h}$ exposure. Based on the comparison of the bacterial viabilities in different treatments (Figure 3A), the inhibition efficiency of AgNPs on bacterial growth was in the following order: Cit@AgNPs > MPS@AgNPs >
MPA@AgNPs > MHA@AgNPs, indicating the surface coating could obviously mediate the antibacterial activities of AgNPs. The surface coating effect that was previously reported indicated that citrate-coated AgNPs exerted higher toxicities when compared to those coated with biodegradable polymer, ${ }^{29}$ although no differences were observed between AgNPs with polyvinylpyrrolidone or oleic acid coatings in an earthworm study. ${ }^{30}$ The antibacterial order observed was exactly consistent with the trend of silver ion release from these AgNPs (Figure 2). This suggested that the released silver ions might mainly contribute to AgNP-induced antibacterial activities.

In order to further clarify the roles of released silver ions, the antibacterial activities were further evaluated by adding the reductase of GSH or ion ligand of $\mathrm{Na}_{2} \mathrm{~S}_{2} \mathrm{O}_{3}$ in $\mathrm{AgNP}$ exposure systems. The results in Figure $3 \mathrm{~B}$ and $\mathrm{C}$ show that both $1 \mathrm{mM} \mathrm{GSH}$ and $0.1 \mathrm{mM} \mathrm{Na}_{2} \mathrm{~S}_{2} \mathrm{O}_{3}$ can efficiently block AgNP exposure-dependent toxicity to E. coli, and the bacterial activities in diverse treatments are completely recovered. It has been shown that GSH could eliminate ROS generation and stabilize AgNPs, and $\mathrm{Na}_{2} \mathrm{~S}_{2} \mathrm{O}_{3}$ could decrease the bioavailability of $\mathrm{Ag}^{+}$by binding with free dissolved $\mathrm{Ag}^{+}$, thus reducing the biological activities of the ionic silver. ${ }^{31}$ The protection of $E$. coli by both $\mathrm{GSH}$ and $\mathrm{Na}_{2} \mathrm{~S}_{2} \mathrm{O}_{3}$ observed earlier suggested that the compromised bacterial growth with AgNP treatments could be dominantly regulated by the oxidation process of AgNPs concomitant with silver ion release and ROS generation.

As the positive control, the effects of silver ions were also tested regarding the antibacterial activities against 

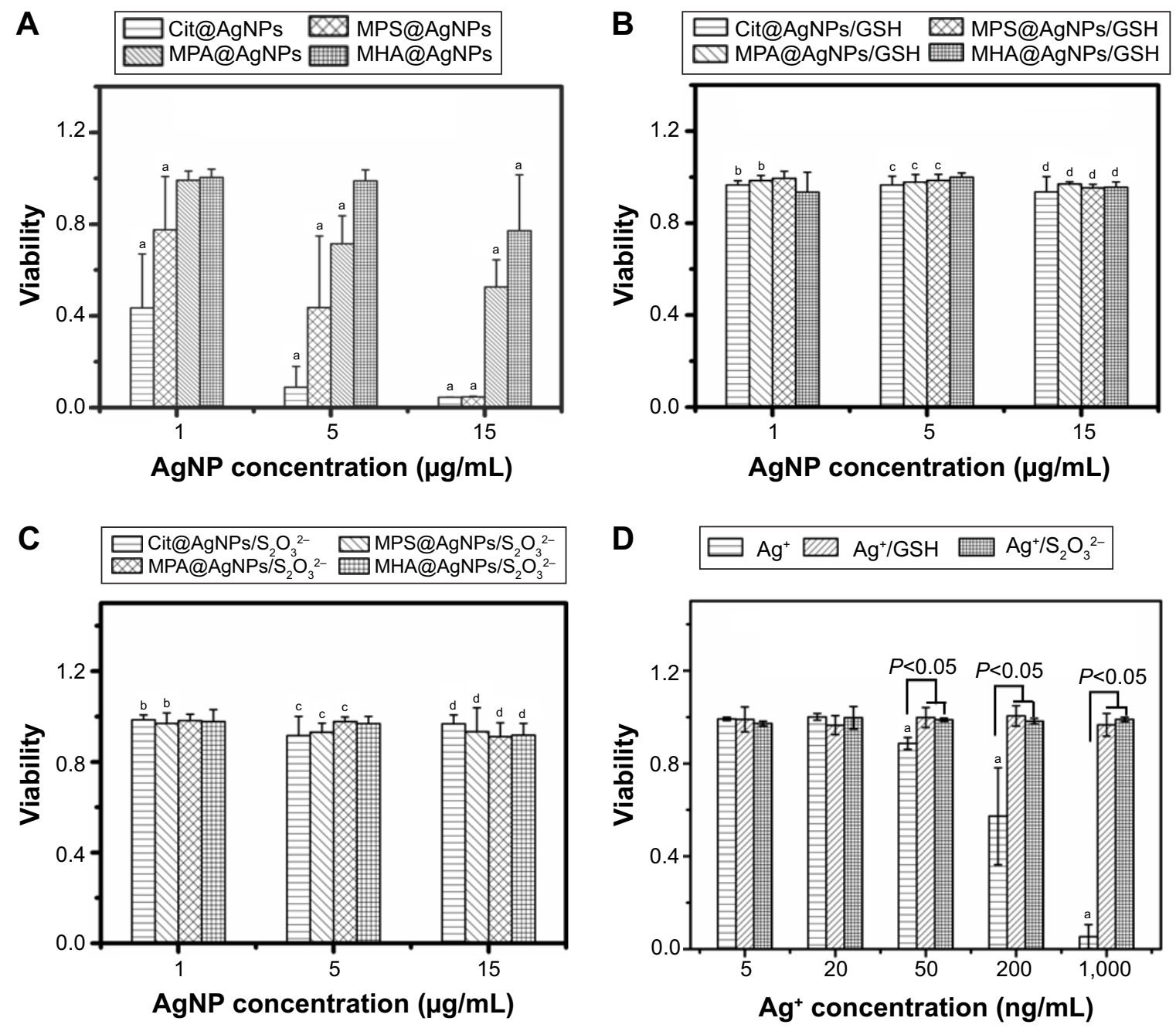

Figure 3 The viabilities of $E$. coli after 6-h exposures of different AgNPs.

Notes: (A) AgNP treatment alone, (B) The coexposure of AgNPs and I mM GSH, (C) The coexposure of AgNPs and $0.1 \mathrm{mM} \mathrm{Na}_{2} \mathrm{~S}_{2} \mathrm{O}_{3}$, and (D) The exposure of $\mathrm{Ag}^{+}$in the absence or presence of I mM GSH or $0.1 \mathrm{mM} \mathrm{Na} \mathrm{S}_{2} \mathrm{O}_{3}$. ${ }^{a}$ Denotes significant difference between each AgNP exposure group and the negative control ( $\left.P<0.05\right)$. ${ }^{b} D e n o t e s$ significant difference between each AgNP $(\mathrm{I} \mu \mathrm{g} / \mathrm{mL})$ plus $\mathrm{GSH}$ or $\mathrm{Na}_{2} \mathrm{~S}_{2} \mathrm{O}_{3}$ coexposure group and I $\mu \mathrm{g} / \mathrm{mL} \mathrm{AgNP}$ exposure alone $(P<0.05)$. 'Denotes significant difference between each $\mathrm{AgNP}(5 \mu \mathrm{g} / \mathrm{mL})$ plus $\mathrm{GSH}$ or $\mathrm{Na}_{2} \mathrm{~S}_{2} \mathrm{O}_{3}$ coexposure group and $5 \mu \mathrm{g} / \mathrm{mL} \mathrm{AgNP}$ exposure alone $(P<0.05)$. ${ }^{d}$ Denotes significant difference between each $\mathrm{AgNP}$ $(15 \mu \mathrm{g} / \mathrm{mL})$ plus $\mathrm{GSH}$ or $\mathrm{Na}_{2} \mathrm{~S}_{2} \mathrm{O}_{3}$ coexposure group and $15 \mu \mathrm{g} / \mathrm{mL} \mathrm{AgNP}$ exposure alone $(P<0.05)$.

Abbreviations: E. coli, Escherichia coli; AgNP, silver nanoparticle; Cit, citrate; GSH, glutathione; MPA, mercaptopropionic acid; MHA, mercaptohexanoic acid; MPS, mercaptopropionic sulfonic acid.

E. coli. The results in Figure 3D show that silver ions can induce significant bacterial growth inhibition in a concentration-dependent manner within the range of 50-1,000 $\mathrm{ng} / \mathrm{mL}$. When compared to AgNPs, silver ions had relatively higher toxicities to $E$. coli, which was consistent with the findings reported previously. ${ }^{7}$ Similarly, both reagents, $\mathrm{GSH}$ and $\mathrm{Na}_{2} \mathrm{~S}_{2} \mathrm{O}_{3}$, could completely recover the suppressed bacterial viabilities of $E$. coli induced by silver ion exposure, which was similar to the results obtained from AgNP exposure experiments. Therefore, it was suggested that AgNP-induced bacterial toxicity could be regulated by silver ion release from the nanosized Ag core.

Nevertheless, when in vitro silver ion release was evaluated, it was found that $6 \mathrm{~h}$ incubation of $1-15 \mu \mathrm{g} / \mathrm{mL}$ AgNPs released low levels of silver ions $(<20 \mathrm{ng} / \mathrm{mL}$, Figure $2 \mathrm{~A})$.
However, 1-15 $\mu \mathrm{g} / \mathrm{mL}$ AgNPs significantly inhibited the bacterial activity, as shown in Figure 3A (bacterial toxicity: 56.5\%-95.5\% for Cit@AgNPs, 32.4\%-95.4\% for MPS@ AgNPs, 0.8\%-47.4\% for MPA@AgNPs, and 0-22.8\% for MHA@AgNPs),while 20 ng/mL silver ions hardly caused any effects (bacterial viability: $\sim 100 \%$, Figure 3D). This indicated that the released silver ions in medium might influence but not dominate AgNP-induced toxicities to E. coli. Accordingly, the effects of the extracellular ROS generation from the in vitro dissolution of AgNPs were also limited. The particle-specific effects could be the predominant mediator in AgNP exposure-induced bacterial growth inhibition, rather than the negligible effects from the released ionic silver or extracellular ROS generated in vitro. It was well known that AgNPs might cause cytotoxicity by a Trojan-horse-type 
mechanism, which explained how AgNPs facilitated the release of free toxic silver ions in cells, where the particles entered and were then ionized. ${ }^{32-34}$ Accordingly, intracellular silver ion release greatly contributed to the antibacterial activities of AgNPs. The surface ligand might also regulate this process in the similar way to what happened in vitro, thus explaining the toxicity order of the four tested AgNPs described earlier. In addition, the intracellular oxidative intermediates $\left(\mathrm{H}_{2} \mathrm{O}_{2}\right.$, etc. $)$ and acidic condition of the organelle (lysosome, etc.) might facilitate the oxidation of the silver core, ${ }^{32}$ potentially inducing the generation of more silver ions and ROS, which could trigger the corresponding biological effects, such as antibacterial activities. With regard to the quantification for the percentage of particulate effect, this is still challenging due to the complexity of the antibacterial mode of AgNPs, and the hot debate on this question continues in the related toxicological studies.

\section{Cit@AgNPs perturb the bacterial respiratory chain through binding with the bacterial membrane, thus increasing intracellular ROS generation}

The cellular uptake of AgNPs might provide the substantial basis for their biological effects occurring in vivo. Using Cit@AgNPs as the representative AgNPs, the distribution of $\mathrm{Ag}$ in $E$. coli was studied after $6 \mathrm{~h}$ exposure. As shown in Figure 4A (left panel), the total Ag levels were similar $\left(\sim 120 \mathrm{ng} / 10^{7} \mathrm{cfu}\right)$ in E. coli samples treated with $15 \mu \mathrm{g} / \mathrm{mL}$ Cit@AgNPs or $0.5 \mu \mathrm{g} / \mathrm{mL} \mathrm{Ag}^{+}$, showing the relatively higher biouptake efficiency of silver in $\mathrm{Ag}^{+}$exposure groups
A

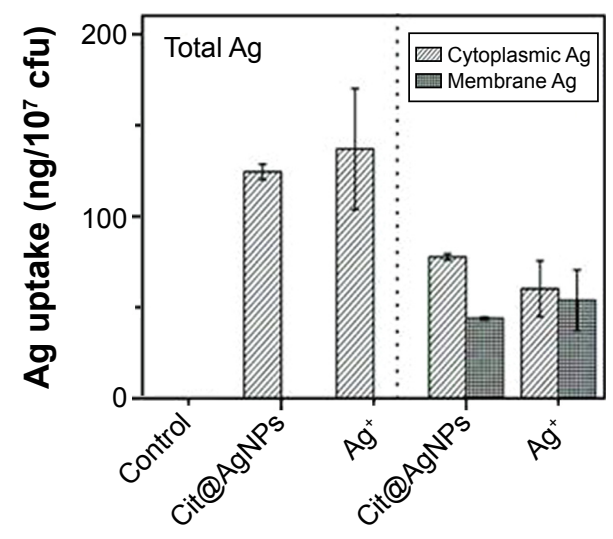

B

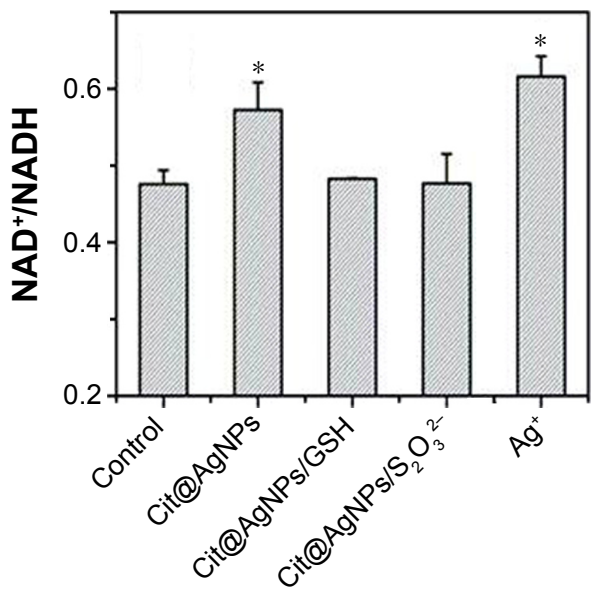

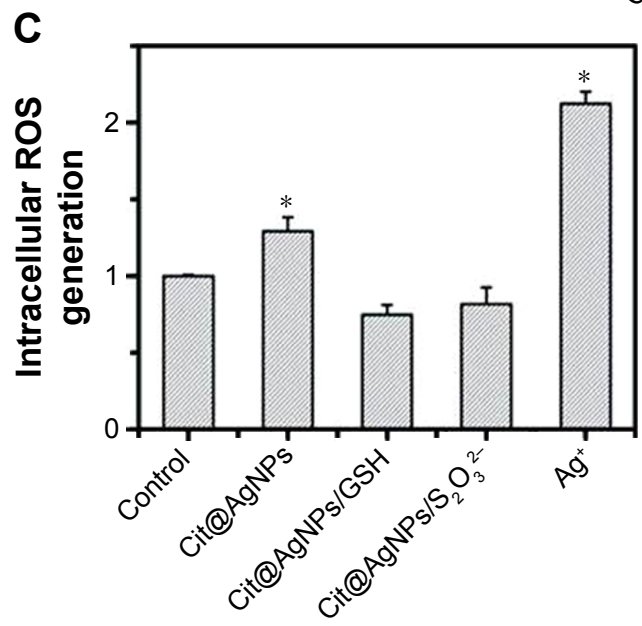

Figure 4 Silver ions perturb bacterial respiratory chain, inducing intracellular ROS generation.

Notes: (A) Total Ag uptake in $E$. coli (left panel) and its distribution (right panel); (B) alteration of NAD $/$ NADH ratio in $E$. coli with different treatments as indicated, $* P<0.05$ versus the negative control; and (C) the intracellular ROS generation. The concentrations of $\mathrm{Cit} @ \mathrm{AgNPs}, \mathrm{AgNO}_{3}, \mathrm{GSH}$, and Na $\mathrm{S}_{2} \mathrm{O}_{3}$ were $15 \mu \mathrm{g} / \mathrm{mL}, 0.5 \mu \mathrm{g} / \mathrm{mL}, \mathrm{I} .0 \mathrm{mM}$, and $0.1 \mathrm{mM}$, respectively, ${ }^{*} P<0.05$ versus the negative control. The exposure lasted for $6 \mathrm{~h}$.

Abbreviations: AgNPs, silver nanoparticles; GSH, glutathione; ROS, reactive oxygen species; E. coli, Escherichia coli; Cit, citrate; MPA, mercaptopropionic acid; MHA, mercaptohexanoic acid; MPS, mercaptopropionic sulfonic acid. 
when compared to Cit@AgNP-treated ones. As the silver ion release ratio of $15 \mu \mathrm{g} / \mathrm{mL}$ Cit@AgNPs was less than $0.02 \mu \mathrm{g} / \mathrm{mL}$ in the medium after $6 \mathrm{~h}$ incubation, particulate Ag greatly contributed to the silver biouptake in Cit@AgNPtreated bacteria. Regarding silver distribution, cytoplasmic Ag levels were a little bit higher than membrane Ag levels, providing the evidence that the extracellular silver either in particulate or in ionic forms could bind with the membrane and enter into the bacterial bodies. The internalization of Ag enabled the biological effects that might happen on the membrane or in cytoplasm through a Trojan-horse-type mechanism for Cit@AgNPs.

It was well known that there were abundant biological enzymes in the bacterial membrane, for example, dehydrogenase, oxidative phosphorylation enzyme, and respiratory chain enzymes. ${ }^{18,35}$ Therefore, the membrane was an important location for energy transfer. More specifically, the respiratory chain in the bacterial membrane was in charge of electron and energy transfer, in which, the reductive coenzyme of NADH was converted into oxidative coenzyme of $\mathrm{NAD}^{+}$, and $\mathrm{O}_{2}$ was reduced to $\mathrm{H}_{2} \mathrm{O}$ by gaining the electron, and the energy was released for the subsequent ATP synthesis in the biological system. ${ }^{35}$ The occurrence of membrane silver might pose high risks for the disruption of the respiratory chain, which led to intracellular NADH consumption and ROS accumulation. ${ }^{36,37}$ The evaluation for the respiratory chain of $E$. coli (Figure 4B) shows that $\mathrm{NAD}^{+} / \mathrm{NADH}$ ratios are significantly increased by both Cit@ AgNPs (0.57) and $\mathrm{Ag}^{+}$treatments (0.62) comparing to the control (0.48), indicating the imbalance of the key elements in the respiratory chain. The addition of GSH or $\mathrm{Na}_{2} \mathrm{~S}_{2} \mathrm{O}_{3}$ efficiently erased the increase in $\mathrm{NAD}^{+} / \mathrm{NADH}$ ratio induced by Cit@AgNP exposure. This result was consistent with the finding from the bacterial viability assay. As the internalized AgNPs might exert hazardous biological effects through a Trojan-horse-type mechanism, the released $\mathrm{Ag}^{+}$could bind/ interact with the essential enzymes on membrane, interrupt the electron transfer, generate excessive ROS, and induce oxidative stress in E. coli. Therefore, the elimination of intracellular ROS and free $\mathrm{Ag}^{+}$by the reagents, $\mathrm{GSH}$ and $\mathrm{Na}_{2} \mathrm{~S}_{2} \mathrm{O}_{3}$, blocked the abnormal effects, such as dysfunction of the respiratory chain, induced by AgNPs.

As mentioned earlier, AgNP exposure might affect the bacterial respiratory chain, potentially causing the imbalance of oxidative-antioxidative system in vivo. The oxidative stress was usually triggered by excessive ROS generation in cells due to the collapse of the antioxidation system. ${ }^{38}$ The intracellular ROS generation was thus evaluated based on DCFH-DA assay. The result in Figure 4C shows that, similar to $\mathrm{Ag}^{+}, \mathrm{Cit} @ \mathrm{AgNP}$ stimulation significantly elevates intracellular ROS level, showing the potential oxidative stress in the treated $E$. coli. The cotreatment with reductase GSH and $\mathrm{Na}_{2} \mathrm{~S}_{2} \mathrm{O}_{3}$ decreased ROS elevation induced by Cit@AgNPs, thus providing efficient protection on the bacteria from the subsequent hazardous impacts. It was widely reported that AgNP-induced biological effects or toxicities were mainly involved with silver ion release or intracellular ROS generation, ${ }^{7,11,39}$ although some studies emphasized that AgNPs could efficiently induce oxidative stress through excessive ROS production, which was distinct from silver ions. ${ }^{17}$ The results obtained herein revealed the concurrence of $\mathrm{Ag}^{+}$and ROS in AgNP-exposed bacterial system, showing the complexity of the antibacterial effects induced by AgNPs.

\section{Cit@AgNP exposure induces oxidative damage in E. coli}

Oxidative stress induced by intracellular excessive ROS generation might pose high risks for the occurrence of oxidative damage, thus causing the structural lesions to the essential biomacromolecules, such as lipids and DNA. The peroxidation of lipid by active free oxidative radicals could produce oxidized products of aldehydes, such as MDA and 4-hydroxyl nonenal (4-NHE), resulting in the loss of cell membrane integrity and even damage on cell structure. ${ }^{22,40}$ MDA, as a common biomarker, was quantitatively measured in E. coli treated with Cit@AgNPs and $\mathrm{Ag}^{+}$to evaluate the potential lipid peroxidation. The results in Figure 5A show that Cit@AgNPs and $\mathrm{Ag}^{+}$treatments slightly increase MDA levels in E. coli, indicating the existence of lipid peroxidation due to oxidative damage. Similar to the findings from bacterial activity, $\mathrm{NAD}^{+} / \mathrm{NADH}$ ratio, and ROS assays, the protection effect was observed in the coexposure groups of Cit@AgNPs plus GSH and Cit@AgNPs plus $\mathrm{Na}_{2} \mathrm{~S}_{2} \mathrm{O}_{3}$, which further confirmed that $\mathrm{Ag}^{+}$release and ROS generation played important roles in the mediation of Cit@AgNP-induced oxidative damage in E. coli.

Morphological observation using scanning electron microscopy might provide direct evidence on the surface changes in the organisms. Figure 5B shows that the control $E$. coli is in rod-like shape with the longitudinal diameter of $\sim 2 \mu \mathrm{m}$. The bacterial surface was smooth and intact. The treatments of Cit@AgNPs and Ag $^{+}$caused cell collapse of $E$. coli structure, which was characterized by the rough surfaces and even breakdown in some bacterial bodies (Figure $5 \mathrm{C}$ and D). The coincubation of GSH and $\mathrm{Na}_{2} \mathrm{~S}_{2} \mathrm{O}_{3}$ 
A

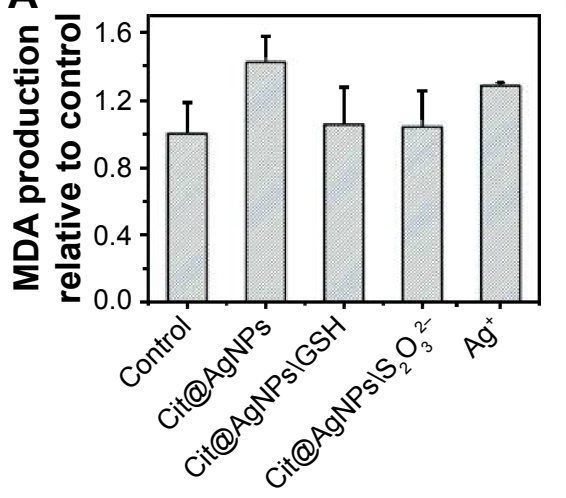

B

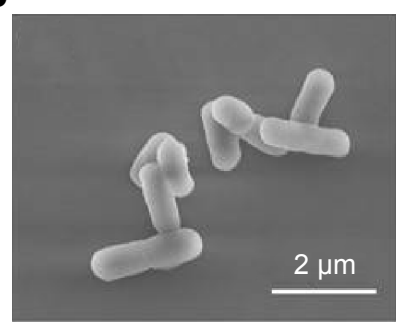

C

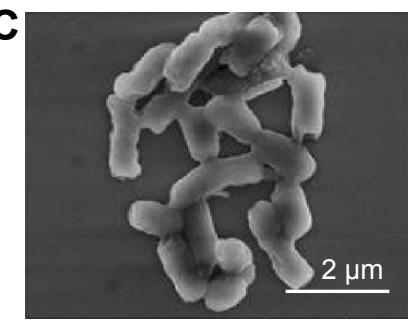

E

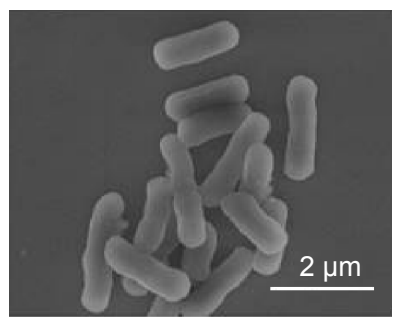

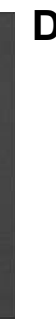
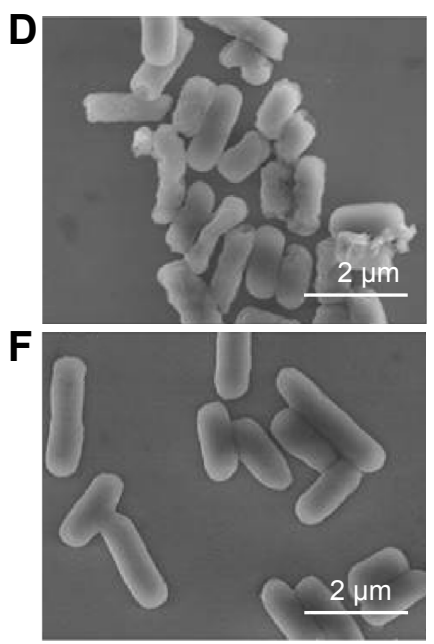

G

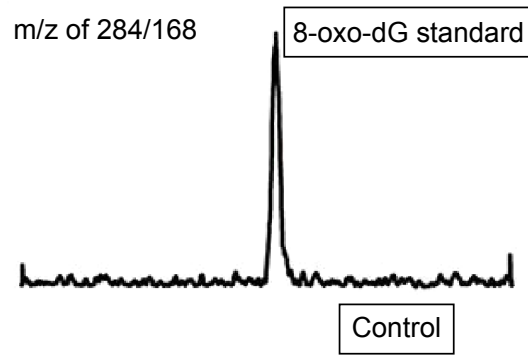

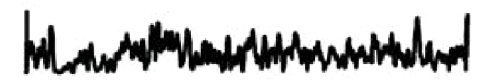
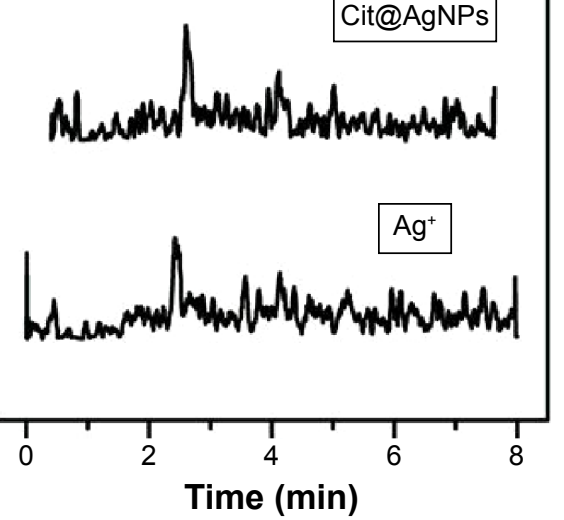

Figure 5 Oxidative damage and morphological changes in E. coli stimulated by Cit@AgNPs.

Notes: (A) MDA production. Scanning electron microscopic images of $E$. coli samples from the control (B), Cit@AgNPs (C), Ag $(\mathbf{D}), \mathrm{Cit} @ A g N P s$ plus I mM GSH (E), and $\mathrm{Cit@AgNPs} \mathrm{plus} 0.1$ mM Na $\mathrm{S}_{2} \mathrm{O}_{3}(\mathbf{F})$. (G) 8-oxo-dG generation in E. coli with different treatments as indicated. The concentrations of Cit@AgNPs and AgNO 3 were I5 and $0.5 \mu \mathrm{g} / \mathrm{mL}$, respectively. The exposure lasted for $6 \mathrm{~h}$.

Abbreviations: 8-oxo-dG, 8-oxoguanine; AgNPs, silver nanoparticles; E. coli, Escherichia coli; GSH, glutathione; MDA, malonyldialdehyde; Cit, citrate; MPA, mercaptopropionic acid; MHA, mercaptohexanoic acid; MPS, mercaptopropionic sulfonic acid.

efficiently blocked the morphological damages caused by Cit@AgNP exposure, and the bacterial bodies were as intact as the controls. This finding was consistent with the results of MDA assay and the protection effects of these two reagents observed earlier.

The imbalance of oxidation-antioxidation system due to intracellular excessive ROS generation might also lead to deleterious effects, such as the alterations of DNA structure. ${ }^{41,42}$ The oxidative modification on certain sites of DNA could form representative products. For example, hydroxylation on the eighth carbon atom of guanine moiety produced 8-oxo-dG, which was commonly used as a sensitive biomarker for DNA oxidative damage. The analysis based on LC-MS/MS showed that no detectable levels of 8-oxo-dG $(<2 \mathrm{nM})$ were found in E. coli samples with diverse treatments (Figure 5G), revealing that, in contrast to lipid peroxidation, no DNA oxidative damage occurred upon $\mathrm{AgNP}$ or $\mathrm{Ag}^{+}$stimulations.
In summary, the coating ligands of AgNPs regulated $\mathrm{Ag}^{+}$release in vitro and in vivo. By binding with or entering into the plasma membrane, AgNPs disturbed the respiratory chain in $E$. coli and caused oxidative stress through a Trojanhorse-type mechanism. The corresponding deleterious effects, including lipid peroxidation, loss in the integrity of plasma membrane, and bacterial growth inhibition, could be efficiently attenuated by the coexposure of GSH or $\mathrm{Na}_{2} \mathrm{~S}_{2} \mathrm{O}_{3}$, confirming the critical roles of ROS concomitant with the released $\mathrm{Ag}^{+}$in antibacterial activities of AgNPs. The overall proposed process is sketched in Scheme 1.

\section{Conclusion}

In this study, ligand-dependent $\mathrm{Ag}^{+}$release was found based on the comparison of four $10 \mathrm{~nm}$-sized AgNPs coated with Cit, MPA, MHA, and MPS, respectively. These ligands possess different coordination atoms, carbon chain lengths, and terminal groups. The particulate Ag coated with citrate 


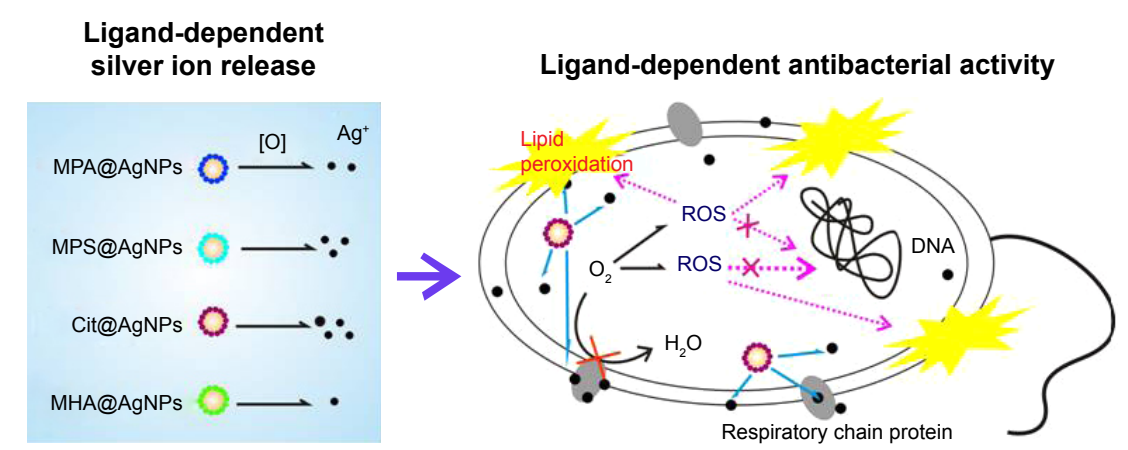

Scheme I The ligands regulate the antibacterial activities of AgNPs by controlling Ag+ release and oxidative stress through a Trojan-horse-type mechanism.

Notes: More specifically, the internalized $\mathrm{AgNPs}$ release $\mathrm{Ag}^{+}$in a ligand-dependent manner, perturb the membrane respiratory chain, cause excessive $\mathrm{ROS}$ generation, lipid peroxidation, and loss of the plasma membrane integrity, thus exerting antibacterial properties.

Abbreviations: AgNPs, silver nanoparticles; ROS, reactive oxygen species; Cit, citrate; MPA, mercaptopropionic acid; MHA, mercaptohexanoic acid; MPS, mercaptopropionic sulfonic acid.

had the highest $\mathrm{Ag}^{+}$release ratio and the strongest antibacterial activities against $E$. coli due to its short carbon chain and weak binding atom of oxygen, when compared to the other three tested AgNPs. A Trojan-horse-type mechanism was proposed as AgNP-induced toxicities could not be fully explained by the in vitro $\mathrm{Ag}^{+}$release. Using Cit@,AgNPs as the representative, AgNPs were found to perturb the bacterial respiratory chain through binding with the bacterial membrane, thus raising intracellular ROS generation and the corresponding lipid peroxidation. The findings herein provided new insights into roles of ligands in regulating antibacterial properties of nanosilver and the underlying molecular mechanism. The optimization of the surface ligand, such as coordination atom, carbon chain, and terminal group, is a very promising strategy in nanoparticle manufacture for multiple commercial application purposes.

\section{Acknowledgments}

This research was jointly supported by the National Basic Research Program of China (2015CB453102), National Natural Science Foundation of China (21307151, 21621064 , 21477153, 21677063, and 21461142001), and the Chinese Academy of Science (14040302, QYZDJ-SSW-DQC017). We thank Prof Zhixiong Xie from Wuhan University for kindly providing E. coli strain of MG 1655 and Dr Hua Huang from Research Center for Eco-Environmental Sciences for helping with the measurement of 8-oxo-dG.

\section{Disclosure}

The authors report no conflicts of interest in this work.

\section{References}

1. Marambio-Jones C, Hoek EMV. A review of the antibacterial effects of silver nanomaterials and potential implications for human health and the environment. J Nano Res. 2010;12(5):1531-1551.
2. Wilson Center [webpage on the Internet]. An Inventory of Nanotechnology-Based Consumer Products Introduced on the Market. Available from: http://www.nanotechproject.org/cpi. Accessed July 2015.

3. Kim JS, Kuk E, Yu KN, et al. Antimicrobial effects of silver nanoparticles. Nanomed Nanotechnol. 2007;3(1):95-101.

4. Vertelov GK, Yu AK, Efremenkova OV, Olenin AY, Lisichkin GV. A versatile synthesis of highly bactericidal Myramistin ${ }^{\circledR}$ stabilized silver nanoparticles. Nanotechnology. 2008;19(35):355707.

5. Smetana AB, Klabunde KJ, Sorensen CM. Synthesis of spherical silver nanoparticles by digestive ripening, stabilization with various agents, and their 3-D and 2-D superlattice formation. $J$ Colloid Interface Sci. 2005;284(2):521-526.

6. Alivisatos AP. Semiconductor clusters, nanocrystals, and quantum dots. Science. 1996;271(5251):933-937.

7. Levard C, Hotze EM, Lowry GV, Brown GE Jr. Environmental transformations of silver nanoparticles: impact on stability and toxicity. Environ Sci Technol. 2012;46(13):6900-6914.

8. Nel A, Xia T, Madler L, Li N. Toxic potential of materials at the nanolevel. Science. 2006;311(5761):622-627.

9. Liu J, Hurt RH. Ion release kinetics and particle persistence in aqueous nano-silver colloids. Environ Sci Technol. 2010;44(6):2169-2175.

10. Ma R, Levard C, Marinakos SM, et al. Size-controlled dissolution of organiccoated silver nanoparticles. Environ Sci Technol. 2012;46(2):752-759.

11. Sotiriou GA, Pratsinis SE. Antibacterial activity of nanosilver ions and particles. Environ Sci Technol. 2010;44(14):5649-5654.

12. Liu J, Sonshine DA, Shervani S, Hurt RH. Controlled release of biologically active silver from nanosilver surfaces. ACS Nano. 2010; 4(11):6903-6913.

13. Kittler S, Greulich C, Diendorf J, Köller M, Epple M. Toxicity of silver nanoparticles increases during storage because of slow dissolution under release of silver ions. Chem Mater. 2010;22(16):4548-4554.

14. Badawy AME, Luxton TP, Silva RG, Scheckel KG, Suidan MT, Tolaymat TM. Impact of environmental conditions ( $\mathrm{pH}$, ionic Strength, and electrolyte type) on the surface charge and aggregation of silver nanoparticles suspensions. Environ Sci Technol. 2010;44(4):1260-1266.

15. Carlson C, Hussain SM, Schrand AM, et al. Unique cellular interaction of silver nanoparticles: size-dependent generation of reactive oxygen species. J Phys Chem B. 2008;112(43):13608-13619.

16. Schmidt M, Masson A, Bréchignac C. Oxygen and silver clusters: transition from chemisorption to oxidation. Phys Rev Lett. 2003;91(24): 243401.

17. Xiong Y, Brunson M, Huh J, et al. The role of surface chemistry on the toxicity of Ag nanoparticles. Small. 2013;9(15):2628-2638.

18. Asharani PV, Low Kah Mun G, Hande MP, Valiyaveettil S. Cytotoxicity and genotoxicity of silver nanoparticles in human cells. ACS Nano. 2008;3(2):279-290 
19. Holt KB, Bard AJ. Interaction of silver(I) ions with the respiratory chain of Escherichia coli: an electrochemical and scanning electrochemical microscopy study of the antimicrobial mechanism of micromolar Ag+. Biochemistry. 2005;44(39):13214-13223.

20. Bastús NG, Merkoçi F, Piella J, Puntes V. Synthesis of highly monodisperse citrate-stabilized silver nanoparticles of up to $200 \mathrm{~nm}$ : kinetic control and catalytic properties. Chem Mater. 2014;26(9): 2836-2846.

21. Wiegand I, Hilpert K, Hancock RE. Agar and broth dilution methods to determine the minimal inhibitory concentration (MIC) of antimicrobial substances. Nat Protoc. 2008;3(2):163-175.

22. Porter NA. A perspective on free radical autoxidation: the physical organic chemistry of polyunsaturated fatty acid and sterol peroxidation. J Org Chem. 2013;78(8):3511-3524.

23. Janardhanan R, Karuppaiah M, Hebalkar N, Rao TN. Synthesis and surface chemistry of nano silver particles. Polyhedron. 2009;28(12): 2522-2530.

24. Yang H, Lan Y, Zhu W, et al. Polydopamine-coated nanofibrous mats as a versatile platform for producing porous functional membranes. J Mater Chem. 2012;2(33):16994-17001.

25. Rudkevich DM, Stauthamer WPRV, Verboom W, Engbersen JFJ, Harkema S, Reinhoudt DN. Uranyl UO2-salenes: neutral receptors for anions with a high selectivity for dihydrogen phosphate. J Am Chem Soc. 1992;114(24):9671-9673.

26. Love JC, Estroff LA, Kriebel JK, Nuzzo RG, Whitesides GM. Self-assembled monolayers of thiolates on metals as a form of nanotechnology. Chem Rev. 2005;105(4):1103-1170.

27. Romanska D, Mazur M. Electrochemical preparation of thiol-coated silver nanostructures on highly oriented pyrolytic graphite. Langmuir. 2003;19(11):4532-4534.

28. Grubbs RB. Roles of polymer ligands in nanoparticle stabilization. Polym Rev. 2007;47(2):197-215.

29. Lu W, Senapati D, Wang S, et al. Effect of surface coating on the toxicity of silver nanomaterials on human skin keratinocytes. Chem Phys Lett. 2010;487(1-3):92-96.

30. Shoults-Wilson WA, Reinsch BC, Tsyusko OV, Bertsch PM, Lowry GV, Unrine JM. Effect of silver nanoparticle surface coating on bioaccumulation and reproductive toxicity in earthworms (Eisenia fetida). Nanotoxicology. 2011;5(3):432-444.
31. Li H, Cui Z, Han C. Glutathione-stabilized silver nanoparticles as colorimetric sensor for Ni2+ ion. Sens Actuators B Chem. 2009; 143(1):87-92.

32. Cronholm P, Karlsson HL, Hedberg J, et al. Intracellular uptake and toxicity of $\mathrm{Ag}$ and $\mathrm{CuO}$ nanoparticles: a comparison between nanoparticles and their corresponding metal ions. Small. 2013;9(7):970-982.

33. Wang Z, Liu S, Ma J, et al. Silver nanoparticles induced RNA polymerase-silver binding and RNA transcription inhibition in erythroid progenitor cells. ACS Nano. 2013;7(5):4171-4186.

34. Hsiao IL, Hsieh YK, Wang CF, Chen IC, Huang YJ. Trojan-horse mechanism in the cellular uptake of silver nanoparticles verified by direct Intra- and extracellular silver speciation analysis. Environ Sci Technol. 2015;49(6):3813-3821.

35. Sousa PMF, Videira MA, Bohn A, et al. The aerobic respiratory chain of Escherichia coli: from genes to supercomplexes. Microbiology. 2012;158(9):2408-2418.

36. Cui Y, Zhao Y, Tian Y, Zhang W, Lü X, Jiang X. The molecular mechanism of action of bactericidal gold nanoparticles on Escherichia coli. Biomaterials. 2012;33(7):2327-2333.

37. Kohanski MA, Dwyer DJ, Hayete B, Lawrence CA, Collins JJ. A common mechanism of cellular death induced by bactericidal antibiotics. Cell. 2007;130(5):797-810.

38. Bandyopadhyay U, Das D, Banerjee RK. Reactive oxygen species: oxidative damage and pathogenesis. Curr Sci. 1999;77(5):658-666.

39. Navarro E, Piccapietra F, Wagner B, et al. Nanosilver toxicity: ions, nanoparticles or both? Environ Sci Technol. 2008;42(23):8959-8964.

40. Rival T, Cinq-Frais C, Silva-Sifontes S, et al. Alteration of plasma phospholipid fatty acid profile in patients with septic shock. Biochimie. 2013;95(11):2177-2181.

41. Yin R, Mao SQ, Zhao B, et al. Ascorbic acid enhances Tet-mediated 5-methylcytosine oxidation and promotes DNA demethylation in mammals. J Am Chem Soc. 2013;135(28):10396-10403.

42. Zhao B, Yang Y, Wang X, et al. Redox-active quinones induces genomewide DNA methylation changes by an iron-mediated and Tet-dependent mechanism. Nucleic Acids Res. 2014;42(3):1593-1605. 


\section{Supplementary materials}

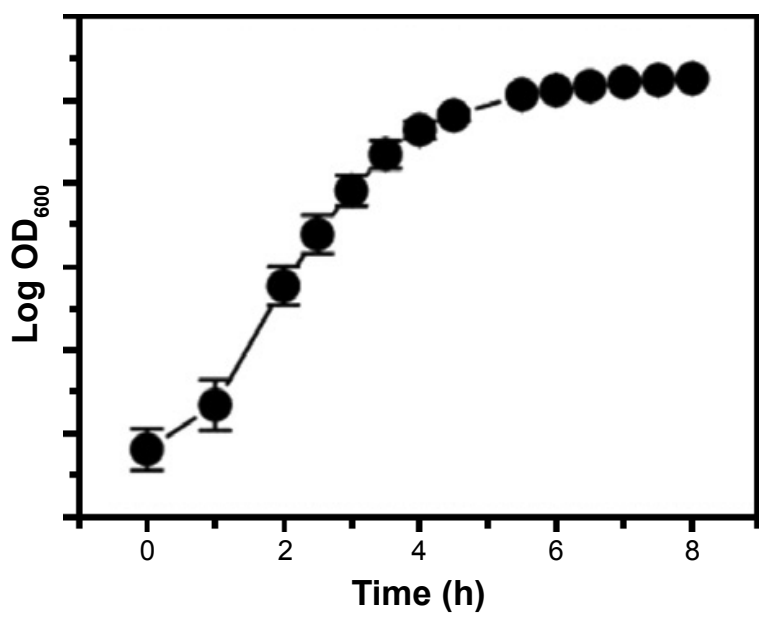

Figure SI Growth curve of E. coli MGI655 in LB growth medium.

Abbreviations: E. coli, Escherichia coli; LB, Luria-Bertani; $\mathrm{OD}_{600}$, optical density at $600 \mathrm{~nm}$.
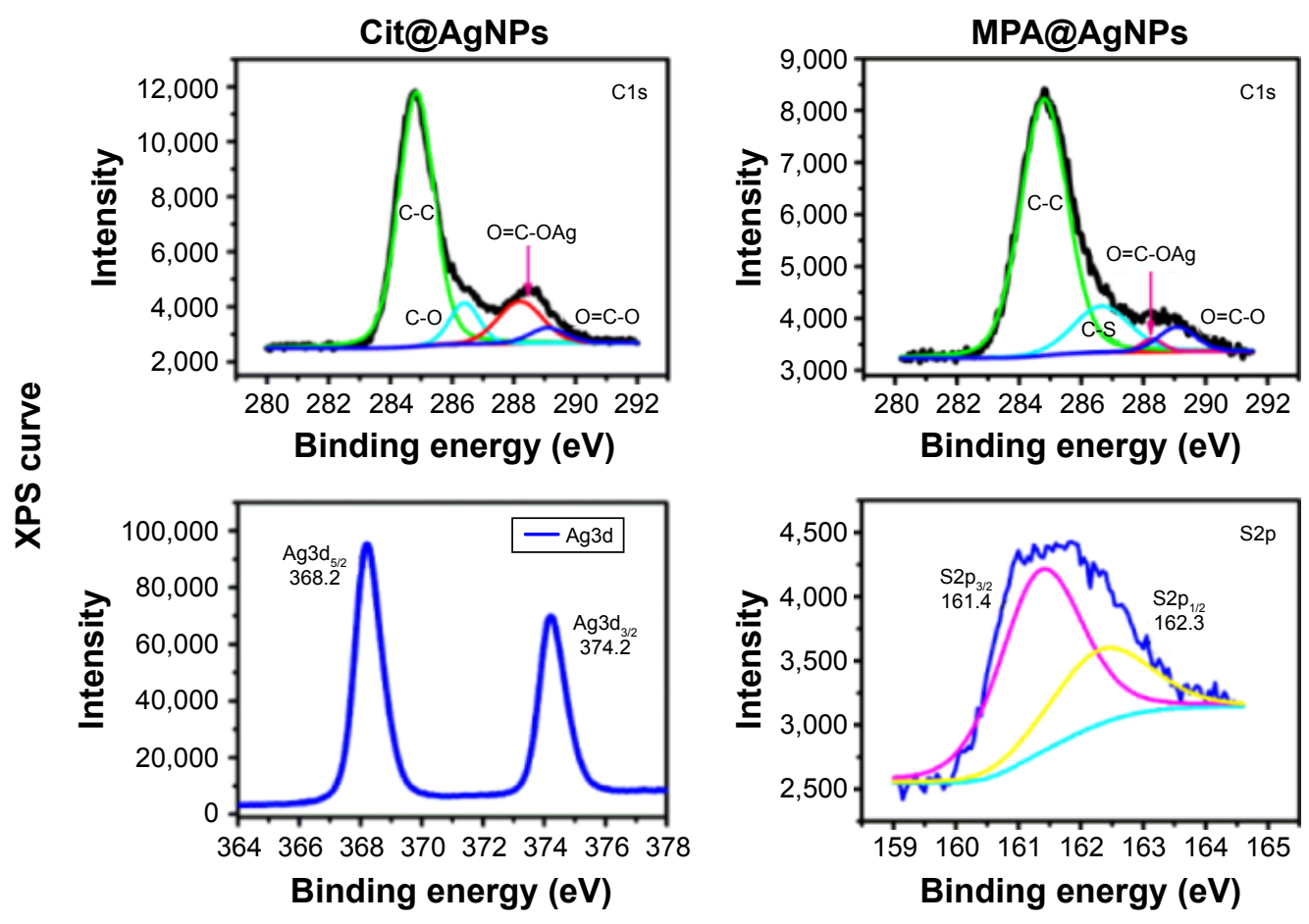

Figure S2 (Continued) 

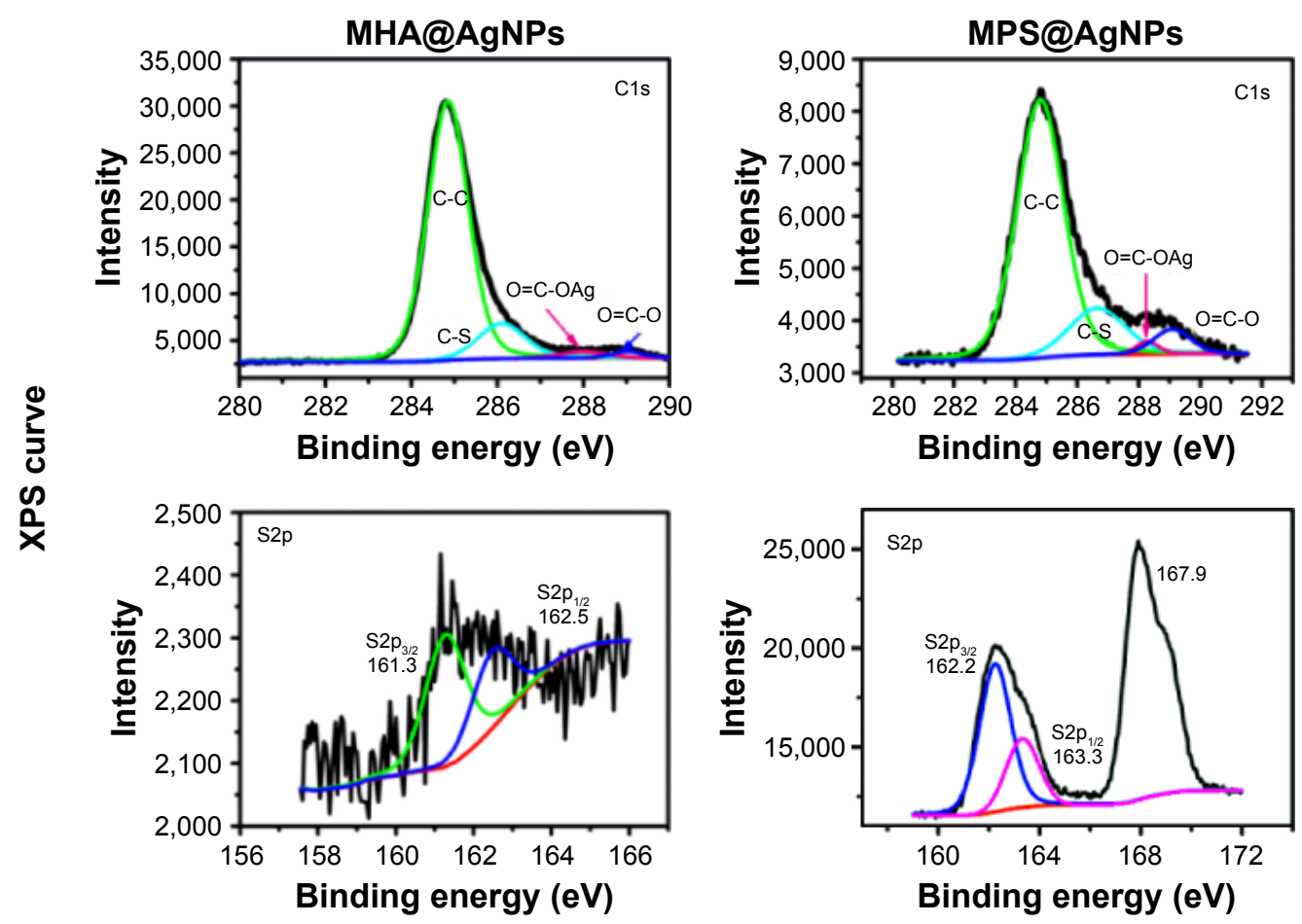

Figure S2 XPS spectrum of AgNPs with four surface ligands, including Cit, MPA, MHA, and MPS.

Abbreviations: AgNPs, silver nanoparticles; Cit, citrate; MPA, mercaptopropionic acid; MHA, mercaptohexanoic acid; MPS, mercaptopropionic sulfonic acid; XPS, X-ray photoelectron spectroscopy.

\section{Publish your work in this journal}

The International Journal of Nanomedicine is an international, peerreviewed journal focusing on the application of nanotechnology in diagnostics, therapeutics, and drug delivery systems throughout the biomedical field. This journal is indexed on PubMed Central, MedLine, CAS, SciSearch $®$, Current Contents ${ }^{\circledR} /$ Clinical Medicine,
Journal Citation Reports/Science Edition, EMBase, Scopus and the Elsevier Bibliographic databases. The manuscript management system is completely online and includes a very quick and fair peer-review system, which is all easy to use. Visit http://www.dovepress.com/ testimonials.php to read real quotes from published authors. 